\title{
Experimental Study of the Advanced Transient Concrete Model on Rein- forced Concrete Columns During Fire Exposure
}

\author{
Ulrich Schneider* and Martin Schneider
}

Univ. of Techn. Vienna, Karlsplatz 13/206, 1040 Wien, Austria

\begin{abstract}
The advanced transient concrete model (ATCM) is an extended model for concrete in compression at elevated temperature that incorporates elastic, plastic and creep strain as a function of temperature and stress history. The ATCM is applied with the material model of the thermal induced strain model. The non-linear model comprises thermal strain, elastic strain, plastic strain and transient temperature strains and load history modelling of restraint concrete structures subjected to fire. The mechanical strain calculated as a function of elastic strain, plastic strain and thermal induced strain. The thermal induced strain is relative independent compared to dependence of Young's Modulus by load history. Actually the term comprises elastic, plastic and (pure) transient creep strains as we will show. A comparison is given between experimental results with cylindrical specimens and calculated results.
\end{abstract}

The equations of the ATCM consider a lot of capabilities, especially for considering irreversible effects of temperature on some material properties. By considering the load history during heating up, an increasing load bearing capacity due to a higher stiffness of concrete may be obtained. With this model it is possible to apply the thermal-physical behaviour of material laws for calculation of structures under extreme temperature conditions.

The effect of load history in highly loaded structures under fire load will be investigated. The theoretical basis is given in this supplement added with an experimental study of concrete columns with various mixes.

\section{INTRODUCTION}

Calculations to predict the deformation rate and load bearing capacity of concrete structures at high temperatures are often based on material models according to Eurocode 2 (EC2). In Europe most of the calculations of structures are based on this model. The model is very usable and provides a high level of safety for members under bending and standard fire test conditions.

The load bearing capacity of concrete structures can be optimized with models representing a transient material behaviour. Models which are approximated by transient data are more realistic. The following investigation describes the potential when using a new transient concrete model. This model considers thermal induced strain with constant external load during heating up. For this model, a realisation of all components of concrete strain is needed. The concrete behaviour is influenced by transient temperature and load history.

A material model for calculation of siliceous aggregate concrete is given in [1]. This new model is an extension of the former Thermal-Induced-Strain-Model (TIS-Model) and is called advanced transient concrete model respective ATCModel (ATCM). This model will be introduced in chapter 2 . Transient conditions during the whole calculation routine are taken into account. The transient load and the real temperature development are considered. Generally an ATCM can

*Address correspondence to this author at the Univ. of Techn. Vienna, Karlsplatz 13/206, 1040 Wien, Austria; Tel: +43 158801 20600;

E-mails: ulrich.schneider+e206@tuwien.ac.at;

e0527948@student.tuwien.ac.at be used for every type of concrete; only some parameter must be changed. This examination is based on ordinary concrete with siliceous aggregates.

Both concrete models, EC2-Model and ATCM are based on different material modelling parameters and the models show a different behaviour for deformations and restraint stresses for structural fire calculations.

Generally the ATCM can be used to represent the results of specimens of every type of ordinary and high strength concrete. This examination is based on ordinary concrete with a siliceous aggregate. A simple structure with a small amount of reinforcement seems appropriate to show especially the effect of a concrete model considering transient (fire) conditions.

The influence of high compressive stresses in concrete section is very high, because the creep strains for transient temperature conditions indicate a significant influence of thermal induced strains. The Eurocode doesn't consider this behaviour explicitly. According to our results, the time of failure is shorter using the EC2-Model for concrete members under high compressive load or restraint compared to the ATCM. In the report we calculate simple structures as columns to show the effect of the Model with the new calculation of the ATCM compared to calculations according to the EC2 concrete model.

Calculations of structural elements, namely columns, were done by FE method using the structural code SAFIR [2] in which the material model using the new transient ATC-Model has been incorporated. This code is suitable to calculate complex structures with different material models. 


\section{TRANSIENT MODEL FOR THERMAL INDUCED STRAIN}

It is generally agreed that the total strain $\varepsilon_{\text {tot }}$ comprises the following parts:

$\varepsilon_{t o t}=\varepsilon_{e l}+\varepsilon_{p l}+\varepsilon_{t r}+\varepsilon_{t h}$,

where:

$\varepsilon_{\text {tot }}$ total strain

$\varepsilon_{e l} \quad$ elastic strain

$\varepsilon_{p l} \quad$ platic strain

$\varepsilon_{t r} \quad$ transient creep strain with transient strain, according

for the effect of the strain increase under increasing temperatures and creep strain which are measured under constant high temperatures

$\varepsilon_{\text {th }} \quad$ thermal strain

The thermal strain is a function different aggregates according to literature $[3,4]$.

To calculate the mechanical strain, a load factor is introduced. This factor takes the load history during heating and cooling into account and is calculated as follows:

$\alpha=\frac{\sigma_{\text {hist }}}{f_{C}\left(20^{\circ} \mathrm{C}\right)}$,

$\sigma_{\text {hist }}$ is the time dependent compression stress due to external loads. In this report the load level $\alpha$ was kept constant during fire exposure. This factor represents the load history and is used for structures which are loaded in the elastic range $\alpha \leq 0.4$ as upper limit for the application of this method.

The reductions of compressive strength and Young's Modulus as a function of temperature for different load histories compared to measurements are shown in [3].

The Young's Modulus as a function of load history and temperature, $E(T, \alpha)$ must be measured according to RILEM [5] or National Codes with respect to the geometry of specimens being used in the high temperature range.

The ultimate strain of the stress-strain relationship is also a function of temperature and $\alpha$. The ultimate strain $\varepsilon_{u}(T, \alpha)$ is calculated as follows [6]:

$\varepsilon_{u}(T, \alpha)=\varepsilon_{u}\left(20^{\circ} C\right)+\Delta \varepsilon_{u}(T) * f(\alpha)$,

with $\varepsilon_{u}(T, \alpha) \leq 7.8 * 10^{-3}$ as an upper limit for all cases $(\alpha=0)$,

where:

$\varepsilon_{u}\left(20^{\circ} \mathrm{C}\right)=2.2 * 10^{-3}$,
$\Delta \varepsilon_{u}(T)=\left[4.2 * 10^{-6}+(T-20) * 5.4 * 10^{-9}\right] *(T-20),(5)$

$f(\alpha)$ is a function of load history. A linear interpolation is applied for a given value of load factor $\alpha \leq 0.4$ :

$f(\alpha)=1(\alpha=0), f(\alpha)=0.227 \quad(\alpha=0.1), f(\alpha)=0.066$

$(\alpha=0.2), f(\alpha)=-0.095(\alpha \geq 0.3)$

Two parts of the stress induced strains at high temperatures i.e. elastic and plastic strains can be included in a stress-strain relationship according to the following equations:

$$
\sigma(t)=f_{c}(T, \alpha) * \frac{\varepsilon(\sigma(t))}{\varepsilon_{u}(T, \alpha)} * \frac{n}{(n-1)+\left(\frac{\varepsilon(\sigma(t))}{\varepsilon_{u}(T, \alpha)}\right)^{n}},
$$

where: $\mathrm{n}=3$ for ordinary concrete, according to $[1 ; 7]$

with $\varepsilon_{p l}(T, \alpha)=\varepsilon\left\{\sigma(t), \varepsilon_{u}(T, \alpha), T, \alpha\right\}-\varepsilon_{e l}\{\sigma(t), T, \alpha\}$.

This transformation is derived from the origin of the Eurocode 2 model. The justification of the exponents based on measured data and is given in $[1,7]$.

Eq. 7 is used to calculate the thermal induced creep strain:

$\varepsilon_{t r}(T, \alpha)=\frac{\varphi^{*} \sigma(t)}{E(T)}-\varepsilon_{p l}(T, \alpha)-\Delta \varepsilon_{e l}(T, \alpha)$,

with: $\Delta \varepsilon_{e l}(T, \alpha)=\varepsilon_{e l}(T)-\varepsilon_{e l}(T, \alpha)$,

$\varepsilon_{t r}(T, \alpha)$ is called "thermal induced creep strain" but the definition is different compared to [8]. The pure transient creep will not be calculated numerically within the proposed calculation procedure described above, but the exact extended relationship is given in equation (7).

The $\varphi$-function for "transient creep" according to [5] and [9] is calculated by the equation (9). It utilizes new parameters as shown in Table 1, those were obtained by older [9] and recent scientific results $[7 ; 10]$ based on ongoing research.

$\varphi=C_{1} * \tanh \gamma_{w} *(T-20)+C_{2} * \tanh \gamma_{0} *\left(T-T_{g}\right)+C_{3}$,

The moisture content of concrete is taken into account using equation (10).

$\gamma_{w}=0.3 * 10^{-3} * w^{0.5}+2.2 * 10^{-3}$, with $\gamma_{w} \leq 2.8 * 10^{-3}$,

$\mathrm{w}$ is the moisture content of concrete in $\%$ by weight whereby $1 \%<\mathrm{w}<4.5 \%$ [4].

Fig. (1) shows the $\varphi$-function for siliceous concrete. The equation (9) above is similar to the equation for creep strain at room temperature. That is why the $\varphi$-function is called "transient creep function" in RILEM literature [11], although 
Table 1. Parameters for Transient Creep Functions of Structural Concretes; According to [4]

\begin{tabular}{|c|c|c|c|c|}
\hline Parameter & Dimension & $\begin{array}{c}\text { Quarzite } \\
\text { Concrete }\end{array}$ & $\begin{array}{c}\text { Limestone } \\
\text { Concrete }\end{array}$ & $\begin{array}{c}\text { Lightweight } \\
\text { Concrete }\end{array}$ \\
\hline \hline $\mathrm{C}_{1}$ & 1 & 2.50 & 2.50 & 2.50 \\
\hline $\mathrm{C}_{2}$ & 1 & 0.70 & 1.40 & 3.00 \\
\hline $\mathrm{C}_{3}$ & 1 & 0.70 & 7.40 & 7.90 \\
\hline$\gamma_{0}$ & ${ }^{\circ} \mathrm{C}^{-1}$ & $7.5^{*} 10^{-3}$ & 700 \\
\hline $\mathrm{T}_{\mathrm{g}}$ & ${ }^{\circ} \mathrm{C}$ & 800 & & 600 \\
\hline
\end{tabular}

it was known that $\varphi$ contains in addition small parts of plastic and elastic strains [9].

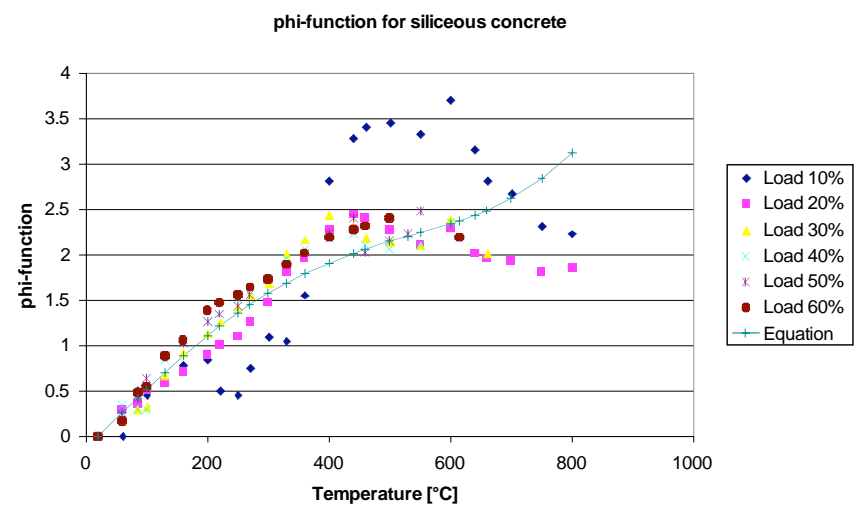

Fig. (1). Transient creep function for siliceous concrete; according to [9].

\section{DEVELOPMENT OF DIFFERENT STRAINS IN COMPRESSION AT HIGH TEMPERATURES}

\subsection{Thermal Strain During Heating and Cooling}

The thermal strain increases in any case by heating up to $650^{\circ} \mathrm{C}$. Above that point thermal strain gradual slightly decreases until the final strain $14.8 \%$ is related at a temperature of $1000^{\circ} \mathrm{C}$ [9]. At each time step there is a final strain according to the reached temperature $T_{\max }$. It is essential to define the maximum thermal strain during heating:

$\varepsilon_{t h}{ }^{n}=\varepsilon_{t h}\left(T_{\max }\right)$

During cooling down the thermal strain is irreversible, as shown in Fig. (2). That is because during heating up to the maximum temperature generally a three dimensional crack system develops. These cracks don't close completely during cooling down, which leads to residual deformations.

\subsection{Elastic and Plastic Strain During Heating Up and Cooling Including Load History}

Any time in the ascending branch the elastic strain is:

$\varepsilon_{e l}{ }^{n}=\varepsilon_{e l}(T, \alpha)$, with "n" for each iteration

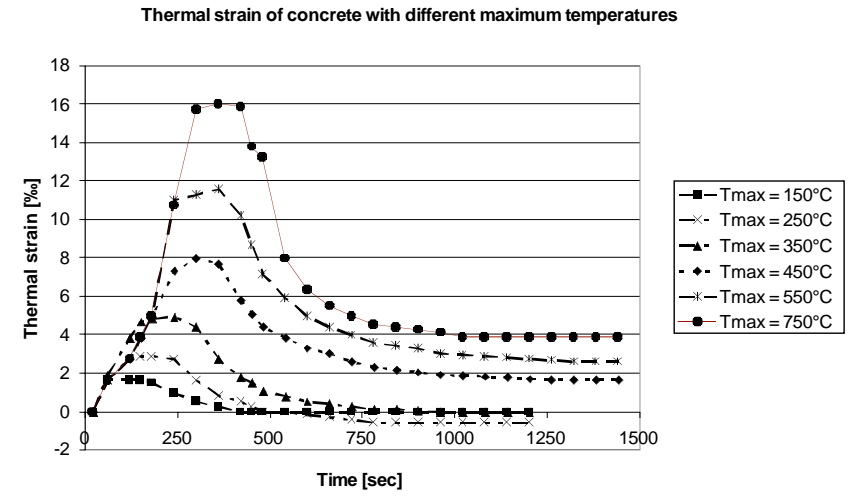

Fig. (2). Thermal strain after heating and cooling for siliceous aggregates concrete; according to [3].

When cooling down, the elastic strain is reversible. The deformation energy subjected to load could be released after heating up assuming that further cracking takes places during cooling.

Plastic strain cannot decrease because it is irreversible. Subsequent by a different behaviour in the ascending and descending branch of the stress-strain-relationship is assumed. The plastic strains are calculated as described before including the load history in stress-strain-relation. If temperature or load history decreases the plastic strain, then the deformation is taken as constant. The mechanical strain must be separated in the elastic and the plastic parts and must be separately studied for the cases heating and cooling. Only with this assumption the behaviour could be considered in a nonlinear calculation.

$\varepsilon_{p l}{ }^{n}=\varepsilon_{p l}\left(T_{\max }, \alpha\right)$, with "n" for each iteration

For cooling down the deformations are constant. This must be taken into account in the nonlinear concrete model. In the range of $\varepsilon_{p l}+\varepsilon_{e l} \geq \varepsilon_{u}$ it may be calculated according to the linear model of EC2 given in Table 2, where:

$\varepsilon_{u}(T, \alpha)$ ultimate strain in ascending branch

$\varepsilon_{u, 1}(T, \alpha)$ maximum strain of the descending branch of stress-strain-relation-ship, 


\subsection{Transient Creep During Heating Up and Load His- tory}

The component of deformation of the creep-function is irreversible. The consideration is discrete in time scale during heating up. For each time step exists a point of the creep function, that belongs to the thermal induced strain and the part of transient creep strain which depend on load history and temperature.

By increasing the temperature and changing the load simultaneously, the parts of plastic and transient creep are irreversible. The part of elastic strain $\Delta \varepsilon_{e l}$ is reversible. The stepwise calculation of strains based on the total strain approach and is done as follows:

$\varepsilon_{t r}{ }^{n}=\varepsilon_{t r}{ }^{n-1}+\Delta \varepsilon_{t r}(T, \alpha)$,

where: $\mathrm{n}$ indicates the new time step with $T=T(n)$ and $\mathrm{n}-1$ the old time step with

$\varepsilon_{t r}{ }^{n} \geq \varepsilon_{t r}{ }^{n-1}$ (temperature increases and stress = constant or increase)

$\Delta \varepsilon_{t r}(T, \alpha)=\varepsilon_{t r}{ }^{n}-\varepsilon_{t r}{ }^{n-1}$,

with $\varepsilon_{t r}{ }^{n}<\varepsilon_{t r}{ }^{n-1}$ (temperature increases and stress decreases)

$\Delta \varepsilon_{t r}(T, \alpha)=\max \varepsilon_{t r}{ }^{n}-\Delta \varepsilon_{e l}{ }^{n}(T, \alpha)$,

Whereas $\Delta \varepsilon_{e l}$ is:

$\Delta \varepsilon_{e l}(T, \alpha)=\varepsilon_{e l}(T, \alpha)-\varepsilon_{e l}(T)$,

From the basic equations we receive:

$$
\begin{aligned}
& \varepsilon_{m}(T)=\varepsilon_{e l}(T, \alpha)+\varepsilon_{p l}(T, \alpha)+\varepsilon_{t r}(T, \alpha), \\
& \varepsilon_{m}(T)=\frac{\sigma(t)}{E(T)} *(1+\varphi), \\
& \varepsilon_{e l}(T)=\frac{\sigma(t)}{E(T)}, \\
& \frac{\varphi * \sigma(t)}{E(T)}=\varepsilon_{p l}(T, \alpha)+\Delta \varepsilon_{e l}(T, \alpha)+\varepsilon_{t r}(T, \alpha),
\end{aligned}
$$

For the pure transient creep we receive from equation (22) finally:

$$
\varepsilon_{t r}(T, \alpha)=\frac{\varphi * \sigma(t)}{E(T)}-\varepsilon_{p l}(T, \alpha)-\Delta \varepsilon_{e l}(T, \alpha),
$$

It is astonishing to observe that the influence of load history originates from plasticity effects and to a small extent from the load effect on the modulus of elasticity. The pure transient function according to equation (22) is obviously of high complexity and up to now not quantitively determined for OPC. The possible data for such a determination are given in the equation cited above and are used in the ATCM.

\subsection{Failure Model}

The point of failure of specimens in a concrete model by FE analysis an approximate failure model must be developed. For this the following procedure is proposed in the calculation.

The failure of plain concrete usually starts due to crack development under compression, i.e. if $\frac{\sigma(t)}{f_{c}(T)}>0$. In the other cases the failure of concrete may occur due to pure tensile stresses or by a combination of both cases including shear stresses. In reality most of the stresses are transferred to the reinforcement steel and the specimens will not fail due to tensile failure of concrete. Without reinforcement the whole concrete structure fails under tension in this case. As long as we consider concrete as basic material the cracking is a dominating factor.

Cracks start directly due to the release of tensile strain and plastic deformation energy exceeding the surface crack energy. The failure may be estimated by the following criteria [9] and [12]:

$$
\begin{aligned}
& \text { - } \quad \text { Temperature: } T_{\max } \geq T_{\text {critical }}(\alpha) \\
& \text { - } \quad \text { Deformation rate: } v\left(\dot{\varepsilon}_{\text {tot }}\right) \geq v\left(\dot{\varepsilon}_{\text {critical }}\right) \\
& \text { Maximum deformation: } \varepsilon_{\text {tot }} \geq \varepsilon_{\text {critical }}
\end{aligned}
$$

In the case of high temperatures, concrete fails under different constant load during heating up, as shown in Fig. (3).

Note that the maximum of critical concrete temperature is in the range of 850 to $950^{\circ} \mathrm{C}$ for loaded structures $[9,12]$. The upper level of fatigue load at this temperature range is $\alpha$ $=0.1$. That means, if you heat up the concrete specimen continuously with a load factor of $\alpha=0.1$ the specimen fails at about $900^{\circ} \mathrm{C}$.

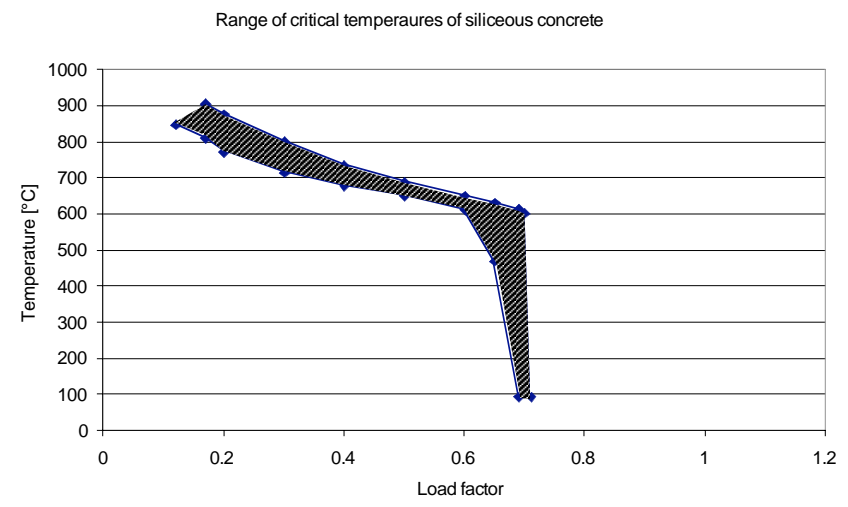

Fig. (3). Critical concrete temperatures of siliceous concrete with constant load during heating up; according to $[9,12]$.

From the test results for the total deformation strains $\varepsilon_{\text {tot }}$ one may conclude, that the deformation rate $v\left(\dot{\varepsilon}_{\text {tot }}\right)$ plays a 
dominant role during the simulation of transient load history. If the maximum deformation rate is exceeded, the concrete fails (range of failure see Fig. (3), after [7]). That means in this case the ratio $\frac{\sigma(t)}{E(T, \alpha)}$ during heating can not be larger than the results of deformation ratio per every second. The deformation rate is shown in Fig. (4). The limit of failure curve in Fig. (7) presents the failure of concrete, if the deformation rate is larger than the limit curve based on the range of failure according to [7]. The observed failure rates $v\left(\dot{\varepsilon}_{\text {tot }}\right)$ range from $5 * 10^{-4} \% / \mathrm{s}$ to $35 * 10^{-4} \%$ o/s depending on the load level and the test temperature. The failure rates are based on the crack development in concrete.

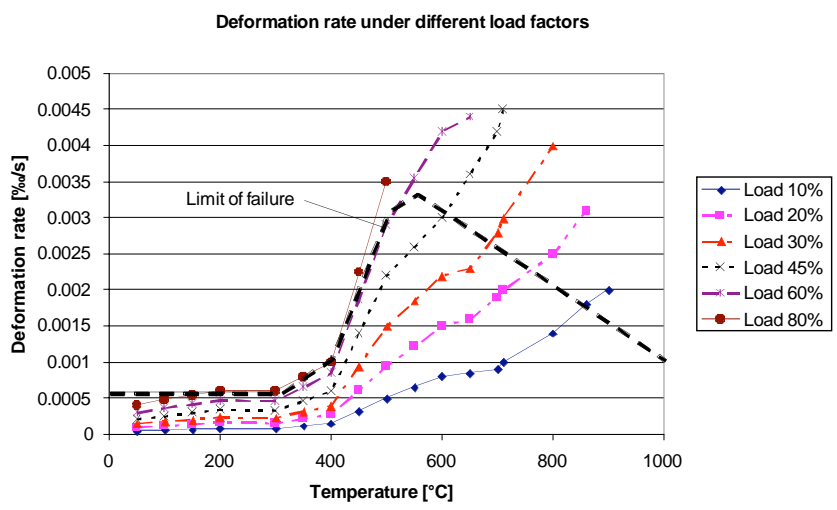

Fig. (4). Deformation rate under different load factors during heating up; according to [8].

Cracks develop in physical-chemical conversion by thermal destruction of CSH phases in cement mortar and of crystal conversion of aggregates respectively [12]. This phenomena's are considered to decrease the compressive strength and the critical temperature. Furthermore cracks are influenced by the kinetic parameters, such as activation energy, reaction rate of dehydration products and reaction rate of concrete aggregates which leads to the time and temperature dependent loss of strength [12]. Drying of concrete at high temperatures is also responsible for cracks [13]. In our model the shrinkage strain during heating is included in the transient thermal strain part which depends on the type of concrete [4]. The ultimate strain of ordinary concrete is considered as a function of load factor $\alpha$ and temperature $T$. It was observed that relating the ultimate strain of loaded specimens at high temperatures just to the ultimate strain at $20^{\circ} \mathrm{C}$ is not sufficient. A part of the larger deformation properties is compensated by the transient creep. The ability of concrete for plasticizing at high loads is depleted, that's why the ultimate strain is unexpected low [14], whereas the total strains under failure conditions are very high.

\section{PRINCIPAL CALCULATIONS AND EXPERIMEN- TAL SETTINGS}

Centric loaded columns were calculated with the new ATC-Model. Measured data were taken from [15] to compare the measured strains over the total length of centrically loaded columns. This is a simple model without considering the accidental eccentricity of the load as recommended by
EC2 for calculation of columns. But it is usable to show the effect of a calculation with the new Model. The results were obtained using the test equipment shown in Figs. (5 and 6 ).

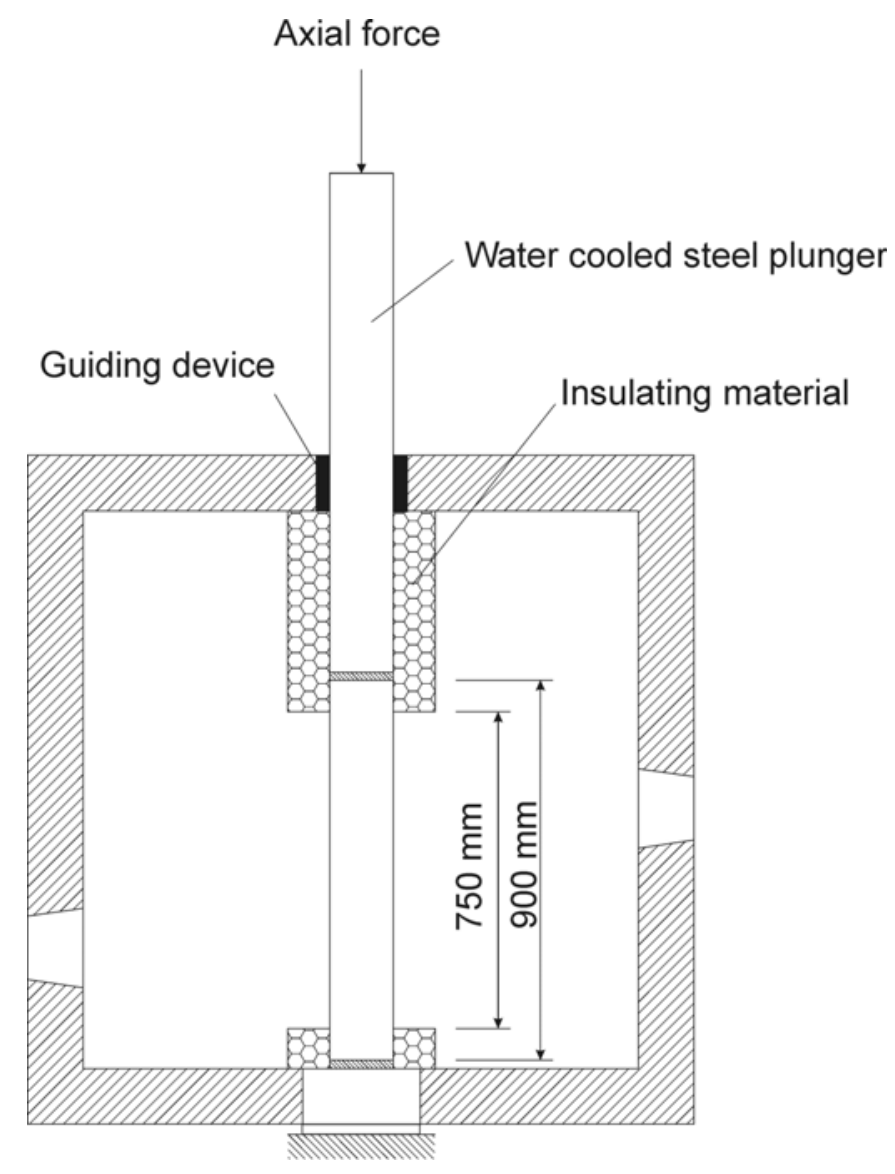

Fig. (5). Sectional drawing testing equipment.

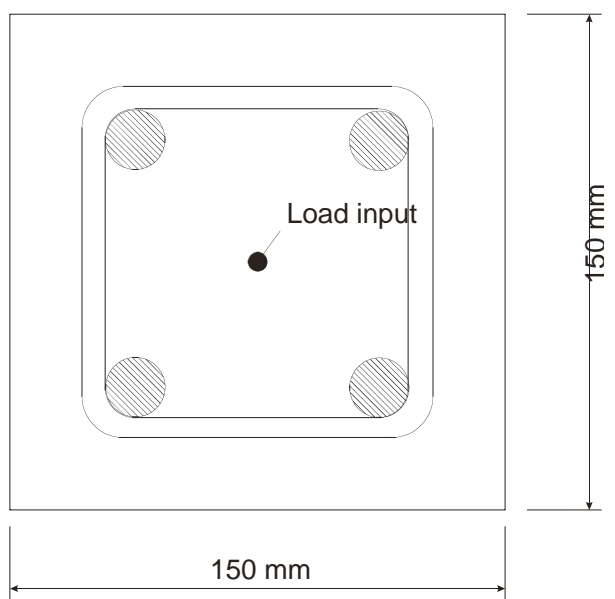

Fig. (6). Cross section of specimens.

In these examples calculations based on fire exposure test in accordance to the Time / Temperature-Time Curve ISO 834 according to [16], as shown in Fig. (7).

The measured data of thermo couples across the cross section showed reasonable results according to the fire curve. The surface of the specimens showed a temperature of 


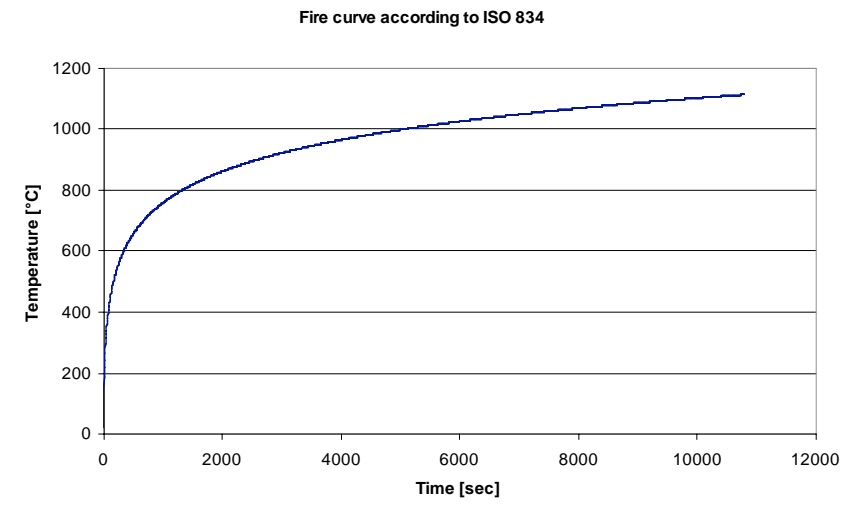

Fig. (7). Fire curve according to ISO 834 according to [16].

$1000^{\circ} \mathrm{C}$ after 60 minutes, that means the fire curve at testing exceeded the standard fire curve. In the centre of the column the temperature reached $300^{\circ} \mathrm{C}$ as a maximum. The thermal analysis of the specimens with FE calculations reasonably reproduced these results, see Fig. (8).

Five different specimens were tested using siliceous concrete mixtures with the following material properties (Reinforcement: 4 bars $\varnothing 20 \mathrm{~mm}$, yield strength $=500 \mathrm{MPa}$, Stirrups $\varnothing 8 \mathrm{~mm}$, Cover $20 \mathrm{~mm}$ ). In Table 2 the mixture parameters are shown in $\mathrm{kg} / \mathrm{m}^{3}$. Table 3 shows the material properties and the test parameter of the load.

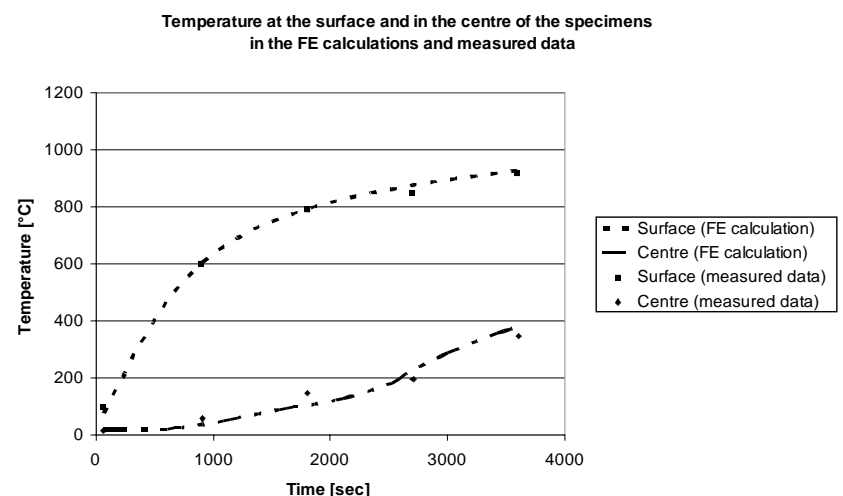

Fig. (8). Temperature curve at the surface and in the centre of the specimen.

Table 3 shows the properties of the different concrete mixes according to standard material test at ambient temperature.

For the tangent modulus (the modulus at zero strain) we used [10]:

$$
E_{c 0 m}=9500 *\left(f_{c k}+8\right)^{\frac{1}{3}}
$$

and for Young's Modulus at ambient temperature we used:

Table 2. Mixture Parameters of Concrete for the Mixtures 1 to 5

\begin{tabular}{|c|c|c|c|c|c|}
\hline & Mixture 1 & Mixture 2 & Mixture 3 & Mixture 4 & Mixture 5 \\
\hline Gravel 2-8 mm & 480 & 480 & 480 & 480 & 480 \\
\hline Gravel 8-16 mm & 960 & 960 & 960 & 960 & 960 \\
\hline Water & 170 & 170 & 170 & 170 & 170 \\
\hline Dispersed silica & 10 & 10 & 10 & - & 10 \\
\hline Dispersed micro silica & - & 1.0 & 2.0 & 2.0 & 2.0 \\
\hline
\end{tabular}

Table 3. Material Properties and Load During Heating of the Mixtures 1 to 5

\begin{tabular}{|c|c|c|c|c|c|c|c|}
\hline \multirow[b]{2}{*}{ Mixture } & \multicolumn{6}{|c|}{ Material Properties } & \multirow{2}{*}{$\begin{array}{c}\text { Test Parameter } \\
\begin{array}{c}\text { Load } \\
{[\mathrm{kN}]}\end{array}\end{array}$} \\
\hline & $\begin{array}{l}\text { Density } \\
{\left[\mathrm{g} / \mathrm{cm}^{3}\right]}\end{array}$ & $\begin{array}{c}f_{c, c u b e, d r y} \\
{[\mathbf{M P a}]}\end{array}$ & $\begin{array}{c}f_{c k} \\
{[\mathbf{M P a}]}\end{array}$ & $\begin{array}{l}E_{c 0 m} \\
{[\mathbf{M P a}]}\end{array}$ & $\begin{array}{c}E_{c m} \\
\text { [MPa] }\end{array}$ & $\begin{array}{c}\text { Moisture } \\
\text { [\% by mass] }\end{array}$ & \\
\hline 1 & 2.377 & 66 & 50 & 36762 & 34251 & 3.6 & 609.2 \\
\hline 2 & 2.357 & 60 & 45 & 35776 & 32963 & 3.7 & 599.4 \\
\hline 4 & 2.352 & 46 & 35 & 33234 & 29821 & 3.2 & 451.9 \\
\hline 5 & 2.344 & 55 & 42 & 34910 & 31865 & 4.0 & 540.8 \\
\hline
\end{tabular}




$$
E_{c m}=\left(0.8+0.2 * \frac{f_{c k}+8}{88}\right) * E_{c 0 m} \text { with } E_{c m} \leq E_{c 0 m}
$$

The concrete mixtures 1 to 5 were altered using a different content fine dispersed micro silica in the mix. The model for ordinary concrete used in our investigation was developed for ordinary concrete without any modifications by addition of small amounts of dispersed silica.

\section{RESULTS}

In the calculations we compared the calculation results obtained by ATC-Model with results of the two EC2-Models and measured data taken from [15]. Fig. (9) shows the different peak stress strain values.

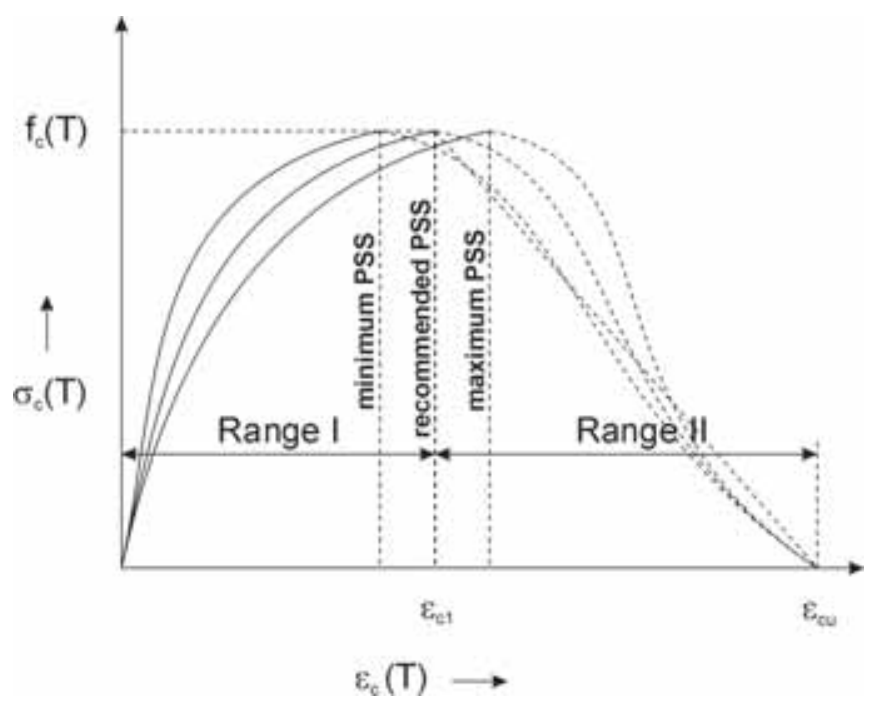

Fig. (9). Stress strain relationship subjected to fire, according to EC2 [15].

Meanwhile the new ENV considers only the maximum value of the peak stress strain, because the concrete behaviour is more realistic at high temperatures.

The results for comparison show the transient longitudinal strain $\varepsilon_{\text {tot }}$ of the tested specimens. Between the three calculation models significant differences are observed. Note that the results of $\varepsilon_{\text {tot }}$ are influenced by different strains according to the ATC-Model and EC2-Model. The ATCM considers the influence of external load during heating on the stress-strain-relationship of concrete and the transient creep effect. Due to the advanced ATC-Model the concrete indicate a wide range of compressive strains at failure, whereas the EC2-Model shows a more or less brittle type of failure. The Figs. (10-14) show the test results of different mixtures.

The measurements started after loading the columns and the calculated results were adapted to the level of deformation at that time. The result of mixture 4 gave the best approximation with respect to the measured data. For this test specimen no micro silica was used and the Young's Modulus is less than 30,000 MPa. The specimen with microsilica indicated a Young's Modulus higher than 32,000 MPa, i.e. the modulus is higher than for ordinary concrete. Generally

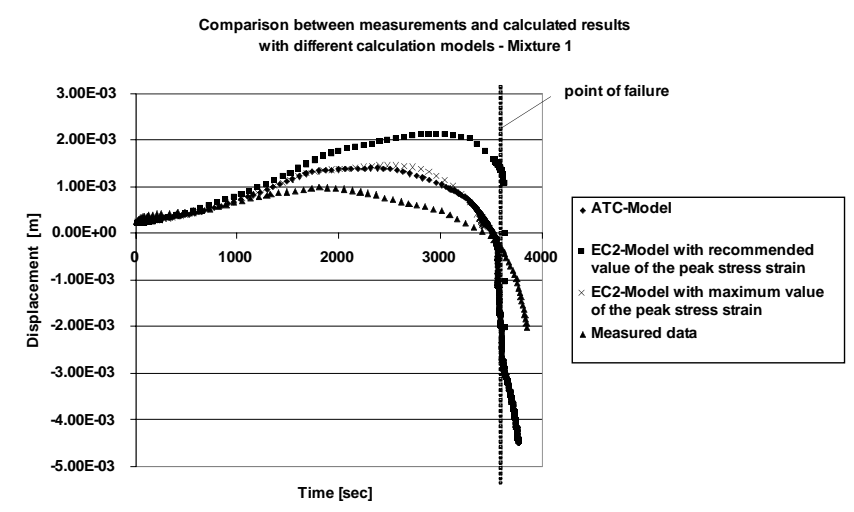

Fig. (10). Calculation results compared to measured data - Mixture 1 .

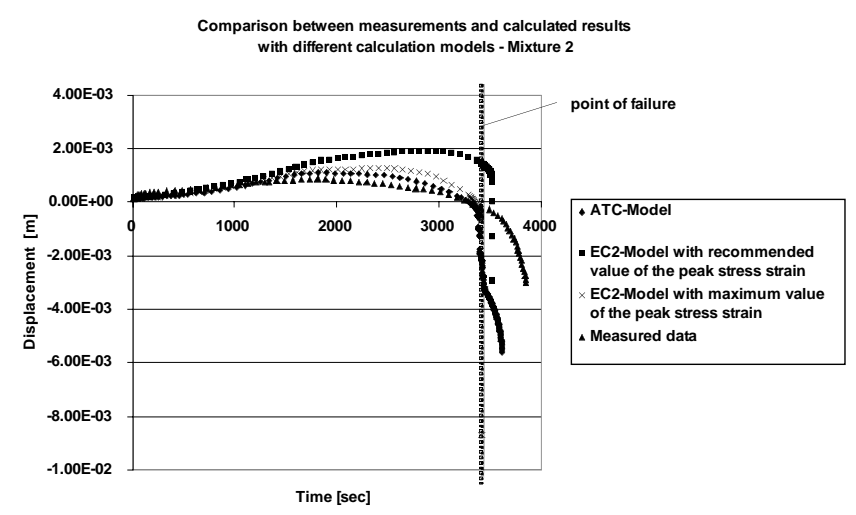

Fig. (11). Calculation results compared to measured data - Mixture 2.

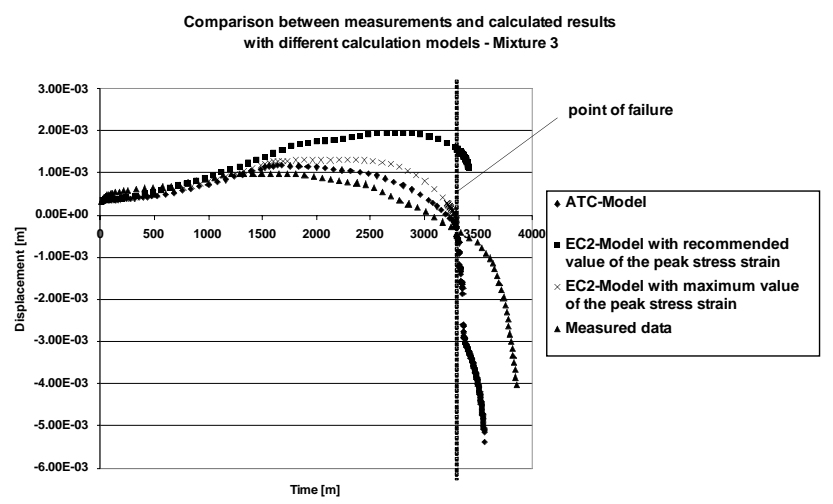

Fig. (12). Calculation results compared to measured data - Mixture 3.

there is a good agreement between measured and calculated results in long time behaviour of the columns.

It was found that for mixtures with higher Young's Modulus the failure in the calculation starts at a time of about 50 minutes. The simulation considers the creep part of the deformation up to this time. It should be noted that the model of concrete was originally developed for ordinary concrete with a Young's Modulus less than 30,000 MPa. With higher Young's Modulus the results of the calculation approximated the measured strains very well up to the time of 50 minutes, but the failure of the specimen is more brittle 


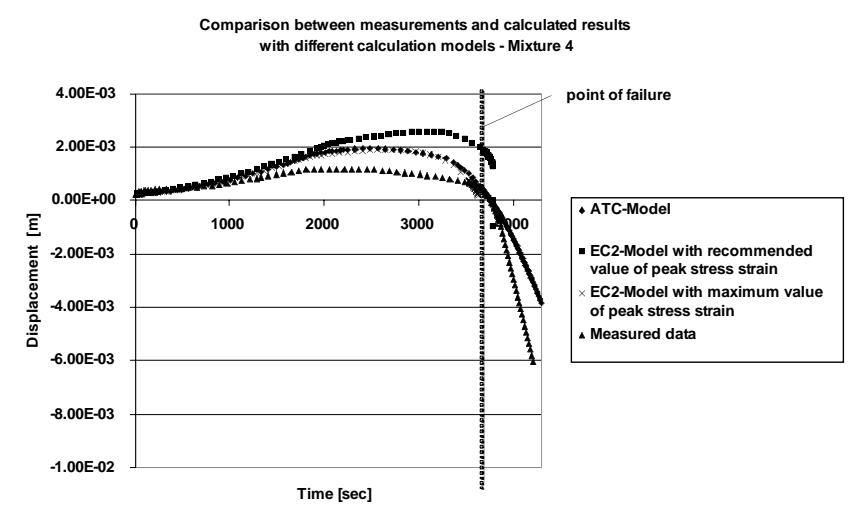

Fig. (13). Calculation results compared to measured data - Mixture 4 (without micro silica).

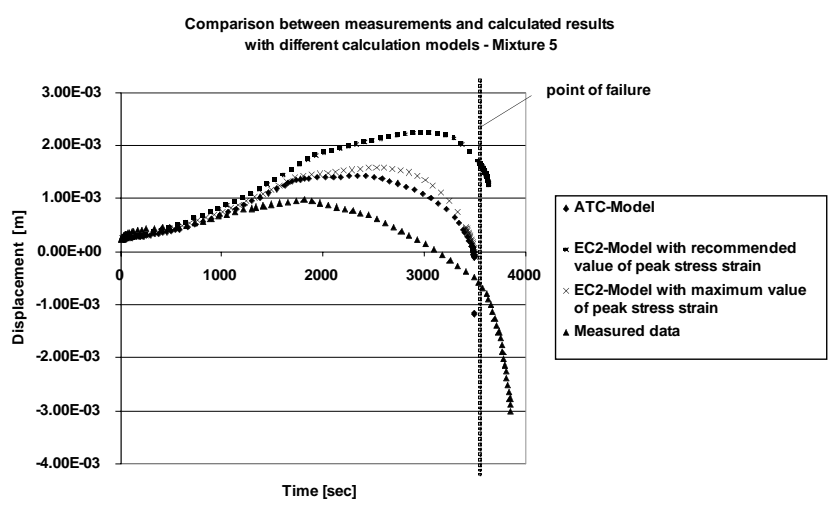

Fig. (14). Calculation results compared to measured data - Mixture 5 .

and starts earlier than the deformations from our material model. The current model doesn't consider the specific reduction of the compression strength of high performance concrete and uses a $\varphi$-function for the transient thermal creep strain according to ordinary concrete. Nevertheless we have obtained a very high accuracy in our calculations with the ATCM for ordinary concrete compared to existing structural tests of concrete with higher Young's Modulus.

The calculation with the average value of ultimate strain according to Eurocode 2 predicts a much higher strain of concrete columns compared to the measured data and the calculations with the ATCM but the time of failure is very good calibrated to the ISO curve. The failure behaviour of concrete with Young's Modulus higher than $32,000 \mathrm{MPa}$ is close to the EC2-Model. The failure point and ultimate strain of mixture 4 is nearly identical to the calculation with the ATCM. Generally it is seen that the strain prediction of the EC2 is less accurate then the calculated data using the ATCModel. For natural fire curves the EC2-Model is not calibrated and may not be used for strain or restraint calculations at high temperatures.

\section{OUTLOOK}

The results of the simulation of loaded concrete structures subjected to fire depend significantly of the material model being used. The strain results of the ATCM are much closer to measured data than the EC2-Model for ordinary concrete. The EC2-Model doesn't consider the transient creep of concrete. That's why the EC2-model cannot account for the total load bearing capacity of the material during the failure of specimen.

The results of the calculation with the ATC-Model for ordinary concrete lead to a comparatively good approximation to measured data. The tests of columns with micro silica concrete indicated a shorter fire duration compared to the calculation results of EC2-Model and ATCM. Generally a brittle failure was observed. For concrete with higher Young's Modulus leading to earlier failure the ATCM worked astonishing good and it seems to us that it is possible to adopt the model easily for applications in the field of high strength concrete HSC or HPC).

The calculation with the ATC-Model has a high potential for optimizing concrete structures, more than the EC2-Model [17] because this Model is not able to determine the total strains with high accuracy and should not be used in the field of HSC or HPC without further calibrations.

The ATCM will be applied to complex structures in further research. For instance calculations of tunnel cross sections are part of our permanent work.

\section{REFERENCES}

[1] U. Schneider, M. Schneider, and J. M. Franssen, "Consideration of nonlinear creep strain of siliceous concrete on calculation of mechanical strain under transient temperatures as a function of load history", in Proceedings of the Fifth International Conference Structures in Fire SIF 08, 2008, pp. 463-476.

[2] J. M. Franssen, "SAFIR. A thermal/structural program modelling structures under fire", Engineering Journal, American Institute of Steel Construction, vol. 42, pp. 143-158, 2005.

[3] U. Schneider, U. Diederichs, and R. Weiß, "Hochtemperaturverhalten von Festbeton", Braunschweig: Sonderforschungsbereich 148 -TU Braunschweig, 1977.

[4] U. Schneider, C. Lebeda, and J. M. Franssen, Baulicher Brandschutz, Berlin: Bauwerk Verlag GmbH, 2008.

[5] U. Schneider, "Mechanical concrete properties at high temperature - recommendation RILEM TC HTC 200", Materials \& Structures, vol. 44, pp. 841-853, 2007.

[6] G. A. Khoury, B. N. Grainger, and P. J. E. Sullivan, "Strain of concrete during first heating to $600^{\circ} \mathrm{C}$ under load", Magazine of Concrete Research, vol. 37, pp. 195-215, 1985.

[7] U. Schneider, Ein Beitrag zur Frage des Kriechens und der Relaxation von Beton unter hohen Temperaturen, Habilitationsschrift, Ed. Heft 42 - Institut für Baustoffe, Massivbau und Brandschutz, TU Braunschweig, Braunschweig, 1979.

[8] U. Schneider, T. Morita, and J. M. Franssen, "A concrete model considering the load history applied to centrally loaded columns under fire attack" in Fire Safety Science - Proceedings of the Fourth International Symposium, 1994, pp. 1057-1068.

[9] U. Schneider, Ein Beitrag zur Klärung des Kriechens und der Relaxation von Beton unter instationärer Temperaturentwicklung, Berlin: Verlag Ernst \& Sohn, 1979.

[10] U. Diederichs, "High-Temperature Behavior of Hardened Concrete", Braunschweig: Sonderforschungsbereich 148 - Brandverhalten von Bauteilen - TU Braunschweig, 1987.

[11] U. Schneider, "Ein Beitrag zur Klärung des Kriechens und der Relaxation von Beton unter instationärer Temperaturentwicklung”, Berlin: Verlag Ernst \& Sohn, 1979.

[12] U. Schneider, "Zur Kinetik festigkeitsmindernder Reaktionen in Normalbeton bei hohen Temperaturen", Braunschweig: Schriftenreihe des Sonderforschungsbereichs 148 - TU Braunschweig, Heft 3, 1974.

[13] A. Cruz, and F. M. Lorenzo, "Dehydratation and rehydratation processes in cementious materials after fire - correlation between micro and macrostructural transformations", in Proceeding fib Task 
Group - Fire Design of Concrete Structures: From Materials Modelling to Structural Performance, Coimbra, 2007, pp. 69-78.

[14] U. Schneider, "Concrete at high temperatures - A general review", Fire Safety Journal, vol. 13, pp. 55-68, 1988.

[15] U. Diederichs, and F. S. Rostásy, "Untersuchungsbericht 5001/0013-Herstellung von Stützenabschnitten aus 10 verschiedenen Mischungen hochfesten Betons und ihre Prüfung unter Brandbeanspruchung nach der Einheitstemperaturkurve gemäß DIN 4102 (ISO 834)”, IBMB TU Braunschweig, 1993.
[16] "Eurocode 2: Design of concrete structures - Part 1-2: General rules - Structural fire design", European Committee for Standardization Brussels, 2004

[17] U. Schneider, M. Schneider, and J. M. Franssen, "Comparison of an approximated method with FEA calculations for the evaluation of the fire resistance of concrete tunnel sections", in Proceedings of International Workshop - Fire Design of Concrete Structures from Materials Modelling to Structural Performance, Coimbra, 2007, pp. 401-412.

(c) Schneider and Schneider; Licensee Bentham Open.

This is an open access article licensed under the terms of the Creative Commons Attribution Non-Commercial License (http://creativecommons.org/licenses/by-nc/3.0/) which permits unrestricted, non-commercial use, distribution and reproduction in any medium, provided the work is properly cited. 